Revista Iberoamericana, Vol. LXXI, Núm. 213, Octubre-Diciembre 2005, 1083-1096

\title{
LA HUMANIZACIÓN DE SAN MARTÍN: NOTAS SOBRE UN MALENTENDIDO
}

POR

Martín KoHan

Universidad de Buenos Aires

\section{EL MITO DE LA DESMITIFICACIÓN}

Una de las falacias más extendidas acerca de los próceres nacionales -mucho más ahora, que la moda de las novelas históricas, hoy imperante en Argentina, la cuenta entre sus equívocos predilectos- es que el discurso de la historia los ha deshumanizado, que los ha erigido como puras estatuas de bronce, y que por lo tanto resulta necesario, o incluso imprescindible, rescatar a esos héroes en sus aspectos estrictamente humanos: no ya en el bronce indeleble, sino como hombres de carne y hueso. El sentido común recogió y potenció esta premisa, en la certeza de que la historia llamada oficial ha construido próceres demasiado perfectos e infalibles, y por ende demasiado lejanos, demasiado ajenos a la gente. Así ha llegado a parecer cierta la necesidad de una compensación o de una revisión de la manera en que la historia ha representado a los héroes nacionales, para devolverlos a su condición de hombres falibles.

Una figura como la de José de San Martín, que corona el panteón argentino de grandes hombres, no podía quedar exenta de los rescates humanizadores, y es acaso el objeto preferido para este tipo de emprendimientos narrativos. Los textos que han fundado su paternidad y su santidad (principalmente, la Historia de San Martín y la emancipación sudamericana de Bartolomé Mitre y El santo de la espada de Ricardo Rojas, pero también los numerosos textos en los que Sarmiento se ocupa de San Martín) encontrarían una variante que se pretende alternativa al encumbramiento histórico, y es así que se despliegan una serie de libros que ya desde sus títulos evidencian la intención de humanizar al prócer por medio de una adecuada penetración en intimidades y psicologías. Textos como, por ejemplo, San Martín. Diez capítulos de su vida íntima de Ismael Bucich Escobar (de 1939), San Martín íntimo de Carlos Ibarguren (de 1950), Agonía interior del muy egregio señor José de San Martín y Matorras de A. Oriol I Anguera (de 1954), Fortaleza sanmartiniana. Bosquejo psicológico de Santiago Wienhauser (de 1964), Perfil humano de San Martín de Erwin Félix Rubens (de 1978), o Los amores ocultos de San Martín de José Luis Thomas (de 1998), hasta llegar al más reciente Don José de José Ignacio García Hamilton (de 2000), coinciden en ese mismo afán: dejar a un lado las exaltaciones hagiográficas y la celebración coral de las grandes gestas militares, ir más allá de la representación de las acciones públicas, para encontrar -en la interioridad de una 
psicología, en la privacidad de las escenas familiares, en la intimidad de los asuntos más personales-a ese "hombre de carne y hueso" que el "héroe de bronce" habría escamoteado.

El despliegue de esta serie de textos abarca más de sesenta años (y, si se considera que El santo de la espada es de 1933, puede advertirse que la aparición de las iniciativas de rescate humano es casi inmediata a la propia consagración hagiográfica). La amplitud cronológica y la heterogeneidad de este corpus, tanto en lo que hace a sus registros discursivos como en lo que hace a sus perspectivas ideológicas, revela qué tan insistentes y qué tan exitosos resultan ser los propósitos de humanización de San Martín. ${ }^{2}$ Los discursos del rescate de ese hombre de carne y hueso que fue San Martín se tornan así no menos significativos -aunque sean siempre mucho más burdos- que los discursos que se supone que lo convirtieron en una estatua elevada y remota, intangible de tan perfecta.

EL HOMBRE DE CARNE Y HUESO

El relegamiento de la exaltación de las grandes hazañas implica, en este caso, una puesta en cuestión del discurso de la historia como tal. ${ }^{3}$ Es el propio discurso de la historia lo que se impugna (y no tal o cual criterio o corriente), en la medida en que se lo considera eficaz para la verificación documental, pero insuficiente para la captación de las facetas humanas de los personajes. ${ }^{4}$ La profundidad de las verdades de ese ser humano que, a fin

\footnotetext{
${ }^{1}$ Así, por ejemplo, se afirma en estos textos: “Alguna vez la austera personalidad del Libertador ha de mostrársenos en la plenitud de su aspecto substancial, con sus pasiones -que las alentó intensamente-, con sus defectos -de que no careció porque era de envoltura humana-, substraído al medio heroico donde la imaginación se complace en admirarlo”(Bucich Escobar 11); “Todos los argentinos [...] lo vislumbran como al héroe de una leyenda y lo contemplan en la personificación estatuaria, montado en su caballo de guerra, evocándolo en los hechos culminantes de sus gloriosas acciones épicas. Pero [...] el hombre íntimo es ignorado [...]. La imagen de San Martín, estereotipada en la mente popular, es la de una personalidad deshumanizada" (Ibarguren 10); "Estamos acostumbrados a un San Martín monumental. Esto tiene la ventaja de magnificar las cosas. Pero tiene la tremenda desventaja de deshumanizarlas. Todos los monumentos de bronce se parecen. Y son fríos [...]. Es menester humanizar a San Martín” (Oriol I Anguera 16 y 19); “Este trabajo se propone [...] captar al San Martín verdadero, no al de la historia popular ni al del mito. Tampoco al de la historia para niños” (Rubens 4); "Era necesario vender un producto acabado y lo suficientemente ideal para que nadie osara encontrar en el santo al hombre” (Thomas 23).

${ }^{2}$ Ese éxito no se debe exclusivamente a las simplificaciones y las banalidades que la moda de las novelas históricas hoy torna imperantes. Un libro de recursos más pobres incluso que lo habitual, como lo es Fortaleza sanmartiniana. Bosquejo psicológico de Santiago Wienhauser alcanzó ocho ediciones entre 1964 y 1979.

${ }^{3}$ Es contundente, en este sentido, el comienzo de Agonía interior..., que empieza exclamando: “¡Basta de Maipú y Chacabuco!” (Oriol I Anguera 13). Lo mismo ocurre con la representación de la santidad sanmartiniana: Rubens aclara que "no se está escribiendo una hagiografía, sino un ensayo lo más exacto posible, para el hombre de hoy" (90). Queda claro que a la recepción ingenua -que sería la de la "historia popular" y la de la "historia para niños"- se le opone la perspicacia de "el hombre de hoy", un hombre moderno y actualizado al que por fin se le va a poder revelar la verdad sobre el Padre de la Patria.

${ }^{4}$ Dice al respecto Oriol I Anguera: "Es curioso lo que pasa con los historiadores profesionales. Mientras pueden discutir a partir de un documento son de un rigor acerado, extraordinario [...]. Pero
} 
de cuentas, según vienen a recordarnos estos textos, ha sido el prócer, está más allá de la vulgar materialidad de la manifestación de los hechos objetivos; y por lo tanto escapa, en su trascendencia, a las verificaciones fácticas de los documentos en los que se basa la historia.

Para captar al prócer en su faceta humana hay que tocar las alturas de su espíritu, dado que -según puntualiza Oriol I Anguera- "para los genios, el cuerpo no es más que un pretexto material”(106). Ese pretexto, sin embargo, resulta insoslayable, ya que no se pueden alcanzar las verdades del alma sin antes develar los enigmas del cuerpo. Y resulta particularmente insoslayable para Oriol I Anguera, médico de origen catalán que trabajó en el Instituto de Fisiología de la Universidad de Córdoba en Argentina: el adentramiento, la búsqueda en la interioridad del sujeto, adopta en su libro una retórica psicologicista tan incierta como frecuente, ${ }^{5}$ pero otros saberes se le agregan: se agregan elementos de la antropología y la fisiología, consideraciones biológicas y genéticas, clasificaciones tipológicas provenientes de una “ciencia del carácter”. Así, San Martín se representa como "un buen respirador" ("lo interesante a mi juicio es la amplitud del vómer”, dice Oriol I Anguera) o como "un tipo linfático-sanguíneo", y en lo que hace a la forma del cráneo, Oriol I Anguera no puede decidirse entre "un braquicéfalo acentuado" y "un dolicocéfalo indiscutible” (68, 70 y 61) (no es su ciencia lo que flaquea: es que hay discrepancias entre las representaciones pictóricas que toma como referencia).

De esta manera, la indagación en la interioridad de San Martín se torna, inesperadamente, indagación en la interioridad, no ya de su subjetividad, sino en la de su cuerpo. El proyecto de efectuar un estudio de ADN sobre los restos de San Martín con el propósito de determinar exactamente su filiación, proyecto que en días más o menos recientes llegó a ocupar la primera plana de algún diario de Buenos Aires, ${ }^{6}$ se revela así como la variante actualizada de un criterio ya existente: el rescate de un San Martín tan

en cuanto estos mismos historiadores tienen que hacer una afirmación de tipo humano de las que surgen sin documento, porque son rasgos de pura psicología, entonces lanzan ingenuidades” (114).

${ }^{5}$ Pese a que Fortaleza sanmartiniana. Bosquejo psicológico anuncia ese afán desde el subtítulo del libro, es en Agonía interior del muy egregio señor José de San Martín y Matorras de Oriol I Anguera donde la operación se desarrolla con mayor intensidad, con enunciados de este tipo: “A juzgar por nuestra experiencia y por lo que nos explican los psicoanalistas de alto vuelo, el hijo menor de una familia numerosa tiene una pendiente abocada al 'mimo' [...]. Sin embargo, nuestro benjamín fue un niño modosito” (132); “El ambiente en que vivió José desde los dos hasta los siete años fue el que corresponde a un neuropático afecto de crisis de situación” (143). Es muy clara la separación de saberes cuando se ocupa de las incertidumbres de la entrevista de Guayaquil: a Oriol I Anguera no le interesan las comprobaciones de los documentos históricos, sino establecer aquello que pueda resultar psicológicamente verosímil: no apela a Lafond, sino a Jung.

${ }^{6}$ La edición del diario Página/12 de Buenos Aires del miércoles 2 de agosto de 2000 titula en su portada: "El ADN de la historia”; y en la bajada dice: "Reclamo sobre el origen de San Martín. Un investigador, acompañado por un descendiente de Alvear, reclamará hoy ante el Senado que se realice un examen de ADN a los restos de San Martín. Quieren dirimir científicamente quiénes fueron los padres del prócer”. El anuncio es acompañado por una ilustración del humorista Rep, en la que se ve a San Martín caído y aprisionado bajo su caballo, en el famoso episodio del combate de San Lorenzo, mientras en un extremo de la imagen, un pintor aparece registrando la escena para una tapa de la revista infantil Billiken. 
humano como verdadero reitera la solicitud de un examen científico de la materialidad de su cuerpo. La premisa según la cual el discurso de la historia habría suprimido la dimensión humana del héroe nacional deriva en una decidida recuperación de su corporalidad más concreta, ya que se supone que el discurso de la historia también la ha suprimido: "hay muchos niños argentinos -establece Oriol I Anguera- a los cuales les costaría creer que el Libertador tenía aparato digestivo” (18).

Es de esta manera peculiar, hecha de clasificaciones de huesos, análisis de sangre, diagnósticos retrospectivos y estudios de herencias biológicas, hecha de gráficos y cuadros sinópticos que expresan la realidad de un temperamento, como se llega a la plasmación de la plena materialidad física de José de San Martín. Esta variante particular de la humanización del prócer roza el registro de la autopsia textual. Y convierte a San Martín, con un brutal sentido de la literalidad, en un hombre de carne y hueso.

LA INTERIORIDAD DEL PRÓCER: EL PRÓCER FUERA DE SÍ

Los textos de humanización de San Martín apelan a menudo a la retórica del develamiento, orientada sobre todo a dos aspectos de su figura: los desequilibrios en su temperamento y los entreveros sexuales de su vida. Una vez que el hombre de carne y hueso ha sido recuperado, se habilita la posibilidad de narrar este tipo de desbordes.

De los diez capítulos de la vida íntima de San Martín que anuncia Ismael Bucich Escobar, hay uno -titulado “La cólera del Libertador”-que apunta en la primera dirección. Lo que se cuenta es un episodio que corresponde al período del retiro de San Martín, y que involucra una serie de intrigas y malentendidos en el mundo diplomático. Como consecuencia de esas intrigas, San Martín se ve enfrentado con el doctor Manuel Moreno, ministro argentino en Londres, a quien trata con especial dureza y -sin advertirlo- con injusticia. La regla general establece que San Martín “era sereno, reflexivo, honrado en su conducta pública y privada” (Bucich Escobar 11). Pero los relatos que quieren rescatar al prócer en su humanidad confirman las reglas a través del tratamiento de las excepciones, o de los momentos de excepción. Así, aunque la serenidad y la reflexividad de San Martín son sus características esenciales, presentan un punto ciego: "Había algo, empero, que alteraba sus nervios y agriaba su gesto, rompiendo el equilibrio de su carácter. No podía aceptar que se le atribuyese la ambición de hacerse coronar emperador, o que mezclasen su nombre en intrigas monárquicas" (12). Ciertos rumores que circulan al respecto son los que lo enquistan con el doctor Moreno, y son, ante todo, los que lo alteran y lo desequilibran.

“La cólera del Libertador” entrega así una versión particular de San Martín: el entendimiento del prócer, "antes clarísimo”, ahora se "obscurece”; quien "sabía regular sus nervios y dominar sus pasiones”, ahora "es arrebatado por la cólera”; es un San Martín “obnubilado", considerado en la precisa circunstancia en que "núblase... la clara luz de su pensamiento” (17, 36 y 47). Frente a los textos históricos de consagración de San Martín, que lo que se supone que hacen, ante todo, es erigirlo en prócer, Bucich Escobar se detiene en un momento de caída. San Martín ha caído, sí, pero ha caído “en la celada” y “en las redes de los intrigantes diplomáticos sudamericanos” (17 y 44). Esas turbias maniobras enredan a quien por lo común trata en términos más transparentes y más honestos, se 
suman al mal estado de su salud, que pudo afectar su equidad, y lo tocan exactamente en su punto de desequilibrio: la sospecha de monarquismo.

Bucich Escobar revela entonces a un San Martín obcecado, arbitrario, alterado emocionalmente. Pero, donde hubo desequilibrio, ha de restablecerse el equilibrio, y donde se produjo cierto descontrol, se ha de regresar al control. Por lo tanto, la injusticia en la que ha incurrido San Martín bien puede repararse, y esa reparación se inscribe en un plano intermedio en el que se cruza la dimensión estrictamente personal y familiar con la dimensión de la representación nacional y política: ese plano en el que la historia nacional se lee también como historia familiar. El hijo político de San Martín, Mariano Balcarce, elige como padrino de su propia hija al teniente coronel Mariano Moreno, sobrino de Manuel e hijo del prócer de Mayo. Se produce así un acercamiento entre las partes, en base a una circunstancia familiar en la que solo parecen tener cabida los apellidos históricamente ilustrísimos.

Tal vez por eso pueden recomponerse dos escenas de reconciliación. Una, del lado de San Martín, queda más bien conjeturada: se dice que, con el correr de los años, llega a sentir "acaso arrepentimiento" (52) (ese arrepentimiento que no terminan de evidenciar los documentos, lo repone Bucich Escobar por medio de una conjetura casi ficcional: “acaso” se arrepiente). La otra escena, la decisiva, es la del propio Manuel Moreno: el ministro, que en primer lugar comprendió a San Martín, luego lo perdona; y cuando, más de quince años después de producido el incidente, llega a la legación de Londres la noticia de la muerte de San Martín, también allí se guardan dos meses de luto como signo de respeto. En el nivel de la representación política y de las manifestaciones simbólicas que sostiene esa representación, en el nivel de los grandes apellidos de la historia argentina que se cruzan en la historia patria pero también en la historia familiar, todo exabrupto queda superado, comprendido y disculpado. Y al héroe argentino no le cabe, no puede caberle otra posibilidad que el homenaje.

El relato de este episodio capta un aspecto fundamental de la lógica de la configuración de los héroes nacionales: no es que no caigan, es que cuando caen se levantan. Una característica fundamental que el episodio del combate de San Lorenzo condensa con inusual nitidez. Se trata de una caída que, a falta de una, funda dos heroicidades: la de San Martín (el héroe que se arriesga, arriesgando su vida, y que cuando se levanta es más héroe de lo que era antes de caer) y la del Sargento Cabral (el héroe que se sacrifica, rindiendo su vida, y se vuelve héroe de la manera más precisa: "haciéndose inmortal”). Lo heroico no radica entonces en la falta absoluta de falencias o debilidades, sino en la capacidad que un héroe tiene para reponerse; no se basa en la perfección de un equilibrio justiciero inalterable, sino en la capacidad para reparar las injusticias cometidas y para recuperar el equilibrio después de haberlo perdido. El héroe se hace en la medida en que es capaz de rehacerse.

Los textos que anuncian el rescate de su dimensión humana se detienen pues en el "pretexto material" del cuerpo del hombre de carne y hueso, para sostener en él la trascendencia desmaterializada de la gloria inmortal; y se detienen en el relato de los momentos excepcionales de un desborde o un desequilibrio, para después apuntalar la verticalidad de la figura del héroe, y devolverle su lugar, debidamente equilibrado, entre los símbolos patrios sostenidos por la representación estatal. 
Cuentos DE ALCoBA

Esa detención en la materialidad del cuerpo de San Martín, planteada con el propósito de revertir la presunta deshumanización histórica de los héroes patrios, se prolonga en una sincera admisión de sus desbordes emocionales. La confluencia de lo uno y de lo otro conduce necesariamente a la representación de algunos episodios de su vida sexual, y es en ese orden de revelaciones, anunciadas con un sentido más periodístico que histórico, ${ }^{7}$ donde los rescates del prócer en su simple condición humana encuentran uno de los fundamentos principales de su insistencia y de su repercusión.

Por más que en el primero de los diez capítulos sobre la vida íntima de San Martín que anuncia Bucich Escobar se defina el entredicho diplomático como un "penoso incidente personal” (23), es Carlos Ibarguren quien toca verdaderamente un asunto de la intimidad de San Martín, y toma nota de otra forma de interioridad: ya no la de los humores, los tejidos y los huesos, sino la de los sentimientos: "Una angustia secreta, íntima, agitaba el espíritu de San Martín: su señora, doña Remedios, se había enfermado gravemente en la Capital” (46). El “drama interior” de San Martín será, para Carlos Ibarguren, motivado ante todo por los asuntos políticos y militares, que son la prioridad en los desvelos del héroe. Pero en el espacio así creado en el texto, en el ámbito que los secretos de la política o de las estrategias militares ya han definido para su intimidad, puede luego agregarse el drama de la historia familiar.

Este “San Martín íntimo” que revela Carlos Ibarguren ya estaría más allá de las convenciones del discurso histórico, en tanto se pretende que en ese registro de consagración patria las angustias personales del prócer no podrían tener cabida. Sin embargo, en la intimidad de este San Martín íntimo no encontramos sino a Remedios, su sacrificada esposa, y en este sentido puede pensarse que la puesta en cuestión de la representación considerada oficial todavía no se ha profundizado lo suficiente.

Los textos de humanización de San Martín avanzan pues en dirección de un develamiento cabal: el develamiento de los “amores ocultos” de San Martín, la revelación chismosa del secreto de sus romances irregulares. En principio, se pretende que las mujeres aparezcan en la vida de San Martín tan solo bajo la legitimidad del signo familiar. Pero si, pese a todo, en ciertas circunstancias de la vida de San Martín aparecen mujeres que no son ni la madre, ni la esposa, ni la hija, ni la hermana, los textos de humanización del Padre de la Patria han de insistir -como en el caso del desborde temperamental- en la disculpa que merece la excepcionalidad del desliz ocasional, o en los méritos de la discreción sanmartiniana, tan contrastada por cierto con la proclividad al escándalo de Simón Bolívar. ${ }^{8}$

\footnotetext{
${ }^{7}$ El primer capítulo del libro de Bucich Escobar, que es el más extenso de todos y el único que de veras avanza en el sentido de alguna revelación sobre San Martín, había sido de hecho publicado -tres años antes de su edición en libro de 1939- en el diario La Razón, y como folletín. ${ }^{8}$ Así, por ejemplo, Oriol I Anguera niega primero toda aventura; y luego, admitiéndola como posible, la disculpa por accidental: "nada encontramos en él del donjuanismo que tan bien sienta a los militares jóvenes. Lo de 'Pepa la Malagueña’ y lo de la 'Protectora’ limeña, aunque verosímil, no puede contar por su singularidad” (206). De manera semejante, Erwin Félix Rubens comienza por una negación tajante, sigue por el reconocimiento de una eventual posibilidad y concluye disculpando
} 
También en estos asuntos, tal como en los de los excesos temperamentales, y tal como en el tropiezo del combate de San Lorenzo, el héroe cae, pero se levanta. Suponiendo que en la indagación de los asuntos de alcoba radicara la posibilidad del rescate del héroe en su condición humana, habría que tener en cuenta una novela como la de José Luis Thomas, porque la escritura de ese texto -apenas menos desenfadada que rudimentaria- no atempera las referencias a los más comprometedores escarceos sanmartinianos, y lleva a la figura del prócer a los términos explícitos de la narración erótica. Si de revelar intimidades se trata, Los amores ocultos de San Martín parece haberse adentrado lo suficiente en ese terreno: extrema el movimiento de indagación en la esfera de lo privado y arma su trama narrativa a partir de la mostración expresa de los pecados del santo: dos o tres amantes, sucesivas o superpuestas, un hijo ilegítimo, una sexualidad que transcurre entre sombras pero que puede ser iluminada convenientemente por la narración literaria. Cae de esta manera la reserva de San Martín, quien era, ante todo, un héroe reservado. Las intimidades de su vida quedan ahora expuestas sin que se ambicione forma alguna de circunspección. ${ }^{9}$

Lo que se definió como oculto, ahora se devela:

Esa tarde entró a la casa de Rosa con una extraña actitud. Algo en su porte y en el rostro permitía entrever a quien lo conociera un poco, la apariencia de una desmesura [...]. Entró como una exhalación hasta la habitación de Rosa. Sin golpear [...]. El hombre ya estaba sobre ella totalmente arrebatado por el impulso erótico. Fue tan rápido el asalto que no hubo tiempo para las consideraciones reflexivas [...]. Y los cuerpos se entregaban al deleite y la atracción sin medida. Como caídos en una extraña alucinación. Rosa recorría con su boca el miembro hasta el ahogo y la desmesura. (Thomas 115, 156 y 157)

Aparece aquí un San Martín arrebatado e irreflexivo; pero ya no de la manera en que lo exponía Ismael Bucich Escobar en los Diez capítulos de su vida íntima, donde eran la injusticia y ciertos manejos de los diplomáticos americanos los que habían enojado al héroe y lo habían puesto fuera de sí. El arrebato y la irreflexión se deben ahora a un impulso erótico, y ese impulso se concreta en la materialidad de los cuerpos de Rosa Campusano y José de San Martín.

Pero el episodio sexual es definido inicialmente como un "asalto" "rápido e inesperado"; del encuentro entre los cuerpos se dice que es una "contienda inesperada"; y, por fin, la consumación del acto resulta "una cabalgadura acompasada”. Las transitadas analogías entre lides amatorias y lides sin más, la correspondencia recurrente entre la

en mérito a la discreción: "no se le conoce a San Martín vida sentimental ni cuentan en su vida las mujeres. Una que otra relación, exclusivamente sexual-en Cádiz, en Santiago de Chile-, mantenidas en estricta reserva" (80).

${ }^{9}$ El mecanismo no es, en última instancia, sustancialmente distinto del que proponía Oriol I Anguera. En realidad, se trata de una misma disposición a subrayar la más pura carnalidad; solo que donde el fisiólogo advertía que "hay muchos niños argentinos a los cuales les costaría creer que el Libertador tenía aparato digestivo", el cuasi pornógrafo advierte: "Me lo han pintado tan virginal. Que no pensé que tuviera pene, ya te lo dije. Pero lo tenía y por lo visto le dio bastante uso" (Thomas 20). 
esfera de la intimidad de San Martín y la esfera de sus intervenciones políticas y militares, ${ }^{10}$ hacen que la descripción minuciosa, detallada y directa de las prácticas sexuales de San Martín conduzca, finalmente, a la imagen de una "cabalgadura acompasada”. Es evidente entonces que nos reencontramos con la estampa escolar del héroe a caballo, erguido y epifánico, la estampa del héroe montando triunfante. Una imagen emblemática que remite a su gesta mayor: la del cruce de los Andes.

\section{LA HUMANIDAD DE UN HÉROE}

Los diversos textos que se han propuesto revertir y corregir la presunta deshumanización histórica de los héroes nacionales reiteran, más allá de sus apreciables diferencias, estas operaciones básicas: recuperar la dimensión del hombre de carne y hueso (llegando, en el límite, al más craso fisiologismo), admitir y evidenciar las imperfecciones y los desaciertos que ese hombre de carne y hueso podía llegar a cometer, e indagar en su vida privada para revelar los secretos de su insondable intimidad (llegando, en el límite, a la más elemental literatura erótica).

Es significativo que la figura de José de San Martín como gran prócer nacional de los argentinos preserve, a través de estos textos, toda su dimensión heroica; es significativo que su consagración como Padre Fundador y como Santo de la Espada no solo no se deteriore, sino que se vea fortalecida por un sistema de representación que en última instancia restablece el equilibrio de todo aquello que pudo tambalear, materializa cuerpos para sublimar trascendencias, y se ocupa de la intimidad como una prolongación de la vida pública, como una forma de continuidad del heroísmo pero por otros medios.

En este sentido, podría considerarse que todos estos textos que apuntan a la interioridad y a los secretos de ese hombre real y concreto que fue San Martín, fracasan en su propósito. Esta manera de entender la cuestión nos permitiría establecer la notoria debilidad de esta clase de libros (algo que no estaría de más, pero que tampoco parece ser la cuestión principal). El hecho, sin embargo, de que San Martín se sostenga acabadamente como gran héroe nacional al cabo de todas estas operaciones dirigidas a desarmar su

\footnotetext{
${ }^{10}$ En efecto, la correspondencia entre la esfera de la intimidad de San Martín y la esfera de sus acciones públicas, permite que incluso sus prácticas más privadas acaben resultando una forma de continuación de las hazañas militares. Es un tópico de la representación de un "San Martín íntimo”, y en la medida en que el tópico se reitera importa poco que la explicitación de la intimidad acentúe su desenfado. El pasaje fluido entre los amores de San Martín y las intervenciones políticas y militares garantiza la superposición entre pasión erótica y pasión patriótica, y este es otro factor decisivo para que la figura del héroe nacional quede perfectamente en pie. Así, el deseo que despiertan las mujeres adquiere un sentido casi militar, en la medida en que se las piensa como soldados: "Eran mujeres especiales. Eran soldados. No sentían la diferencia entre la cama y el cuartel” (Thomas 64); por lo tanto, San Martín "podía amar y gozar sin que esto significara lo que era sino un medio para sus fines libertadores” (42). En la medida en que la pasión erótica llega a identificarse con la pasión patriótica, y todo lo amoroso se militariza, se desvanece la idea de un San Martín desbordado por los deseos del cuerpo, y la representación erótica se reformula como un “doble juego de pasión y estrategia” (40): la sexualidad como prolongación del heroísmo militar hace que incluso la pasión amorosa no sea otra cosa que estrategia de guerra.
} 
heroicidad de bronce para rescatar al hombre de carne y hueso, tiene menos interés como demostración de un eventual desacierto en la concreción de ese emprendimiento, que como demostración de la falacia constitutiva de todas las iniciativas de humanización de los próceres. Esa falacia es constitutiva, porque está en la base de todo el planteo, y vuelve falso (ni logrado ni malogrado, sino esencialmente falso) todo el proceso de rescate humanizador.

La falacia se debe a que no es cierto que el discurso de la historia haya construido héroes ideales, grandes hombres infalibles a los que no se les reconocían errores ni debilidades. En la medida en que la reiterada empresa de humanización de San Martín se propone siempre como una respuesta o incluso como una refutación de la tendencia de la historia a construir próceres demasiado perfectos, no hay modo de que el planteo deje de quedar entrampado en el hecho de que en realidad no es esa la manera en que el discurso de la historia ha consagrado la heroicidad y la santidad de José de San Martín.

Muy por el contrario, los textos de la historia que definieron a San Martín como héroe nacional y lo colocaron en el punto más alto en el panteón de los próceres argentinos, están plagados de objeciones y cuestionamientos, y no vacilan en ofrecer la imagen de un San Martín vacilante o errático; aceptan la posibilidad de dirigirle críticas por sus ideas o por sus intervenciones, y hasta insisten en esas críticas; dan cuenta de ciertos aspectos de su vida íntima, incluso, llegado el caso, de algunos de esos aspectos que se puede llegar a considerar como más comprometedores.

En el caso de Sarmiento, por ejemplo, al narrar la vida de San Martín para la Galería de Hombres Célebres de Chile, se registra esta imagen de Cancha Rayada: "San Martín huía de aquel campo sin darse cuenta bien de lo que le pasaba” (Vida... 129). Este San Martín perdido y desconcertado en ocasión de su único traspié militar, aparecerá en los textos de Sarmiento todavía más perdido y más desconcertado, cuando más adelante incurra en otro traspié, esta vez no en el orden de lo militar sino en el orden de lo simbólico: cuando done su glorioso sable corvo a Juan Manuel de Rosas. Entonces Sarmiento establece:

San Martín era hombre y viejo, con debilidades terrenales, con enfermedades de espíritu adquiridas en la vejez [...]. Aquella inteligencia tan clara en otro tiempo, declina ahora; aquellos ojos tan penetrantes que de una mirada forjaban una página de la historia, estaban ahora turbios [...] y todas sus ideas se confundían. (Viajes... 119)

Lejos de toda idealización, Sarmiento -que ocupa empero un lugar crucial en la consagración histórica de San Martín, entre otras cosas por haber iniciado su reconocimiento en Chile en 1841 y por haber pronunciado en el muelle de Catalinas el discurso de recepción de sus restos repatriados el 28 de mayo de 1880- no prescinde de esta imagen implacable de un San Martín apocado, miope si es que no ciego, que en su vejez chochea.

Bartolomé Mitre irá aún más lejos en 1887 con su Historia de San Martín y de la emancipación sudamericana, porque las críticas que le dirige a San Martín no se refieren tan solo a sus momentos negativos de caída. Desde una enciclopedia general sobre la guerra que se esmera por legitimar, Mitre puntualiza sus críticas a San Martín en el terreno militar, incluyendo las victorias: en la campaña de Chile, no saca toda la ventaja que puede de la superioridad de su caballería; antes de Cancha Rayada, pasa por alto "una de las reglas 
más elementales de la guerra” (Historia de San Martín... II, 354) y conserva una posición que no debió mantener; después de Maipú (y lo mismo después de Chacabuco) comete el error de no activar de inmediato la persecución de los enemigos dispersos, desaprovechando así algunas ventajas que le daba la victoria; tras la toma de Lima comete "graves errores militares, que revelaban la falta de un plan fijo de operaciones” (IV, 113), por lo que paralizó indebidamente la guerra y abandonó equivocadamente al enemigo las provincias de la sierra; reincidió en el error de Chacabuco y de Maipú, al no perseguir inmediatamente a La Serna; ordenó la campaña de Tristán en base a "triviales preceptos de guerra” (IV, 298).

Como se ve, Mitre juzga a San Martín con bastante dureza, con términos que no parecerían corresponder a un relato de consagración, y que sin embargo lo conforman, ${ }^{11}$ ya que no es otro que Mitre quien incorpora a San Martín al cielo de las glorias patrias, junto con Manuel Belgrano, su otro gran biografiado. Si estos son los términos en que Mitre trata a San Martín en lo que hace a estrategias militares, qué no dirá de su inclinación por la monarquía. Más allá de la discrepancia ideológica, Mitre se atreve a la impugnación de la moralidad sanmartiniana, piedra fundamental de su canonización histórica: "El plan de monarquizar al Perú -dice Mitre- despojó a San Martín de su fuerza moral” (VI, 210).

Esta clase de juicios aparece en los textos centrales del discurso de la historia argentina, en esos textos que han compuesto la versión llamada "oficial”; son los textos que han fundado la heroicidad de José de San Martín y lo han consagrado como Padre de la Patria. Y no es cierto que basen su sistema de representación en un encomio sistemático y sin matices, ni es cierto tampoco que sean incapaces de reconocer defectos y flaquezas en los héroes. ${ }^{12}$ La canonización histórica de San Martín es, por lo tanto, bastante más compleja que la sola alabanza, y resulta, por lo tanto, bastante más difícil de desarticular que lo que se tiende a creer.

Los textos del rescate humanizador presumen igualmente que el discurso de la historia omite la representación de la vida cotidiana de los próceres (allí donde se supone

\footnotetext{
${ }^{11}$ Mitre puede ser sumamente drástico: “¡Pero verdaderamente no se concibe dónde el gran capitán americano tenía la cabeza cuando resolvió tal expedición y dictó tan insubstanciales como mal calculadas instrucciones!” (IV, 299).

${ }^{12}$ Mirta Varela advierte estas mismas características en la configuración de los hombres ilustres en la revista infantil Billiken: "Las biografías, ya lo hemos dicho, no son necesariamente ejemplares [...]. Entre el ejemplo de virtud y el relato para niños, Billiken no duda” (77 y 78). Al parecer, es en los libros de lectura escolar donde esos próceres aparecen con una impronta de pareja perfección: "En los libros de lectura, en cambio, es constante la alusión a las virtudes del personaje biografiado como modelo para imitar” (98). Este contraste que establece Mirta Varela entre las representaciones de un medio destinado a la infancia y las representaciones de los textos institucionales -"mientras Billiken intenta convertir cualquier vida en una aventura, los libros de lectura colocan al personaje en un pedestal en el que no se puedan divisar fisuras" (119)- es muy iluminador respecto de lo que ha ocurrido con la difusión escolar de las figuras históricas y con su recepción efectiva por parte de sus destinatarios; pero sería un error prolongar este contraste sobre los textos fundantes del discurso histórico, aun cuando los libros de lectura escolar los invoquen como sus fuentes y los consagren como lugares de la verdad: en los textos fundantes del discurso histórico no hay tal falta de fisuras, como no la hay -según demuestra Mirta Varela, y pese a lo que habitualmente se dice- en la revista Billiken.
} 
que todos somos más o menos iguales, ya que, según se suele decir, no hay grandes hombres para la mirada de un valet). El propio Mitre, sin embargo, que en su gran historia proyecta a San Martín a la dimensión de la historia continental, se plantea igualmente un texto menor que le permite abordar "la historia interna del hombre, principio y fin de sus acciones exteriores” ("Las cuentas...” 452). En "Las cuentas del Gran Capitán”, Mitre analiza la libreta de gastos de San Martín; y será, curiosamente, la expresión fría e impersonal del "lenguaje matemático" la que mejor le sirva para captar a San Martín en los aspectos más personales de su subjetividad. El registro de gastos es un inesperado catálogo de los gustos personales de San Martín: “parece que gustaba de perfumes”; "revela su pasión por las flores"; "su plato predilecto era el asado"; "su bebida favorita era el café”; "la lectura -otra de su grandes pasiones” (460, 461 y 473); y, por cierto, no se pasa por alto la adicción al opio que las notas de gastos del prócer dejan ver. En esta relación entre gastos y gustos, Mitre accede a la vida cotidiana de San Martín, y en la enumeración de sus placeres o de sus necesidades se insinúa la materialidad de su cuerpo.

Claro que es Ricardo Rojas quien profundiza resueltamente esta indagación en la intimidad de San Martín y el reconocimiento profano de su humana carnalidad. Contrariando lo establecido por los lugares comunes acerca de los ocultamientos que requeriría la santificación del prócer, es precisamente en El santo de la espada donde se cuentan las relaciones de San Martín con una prostituta de Cádiz: “Allá conoció a una mujer, a quien llamaremos Pepa la Gaditana, única silueta femenina cuyo perfil vemos pasar, sugestivamente, en la penumbra de aquellos días” (37). Y se cuenta también la relación de San Martín con Rosa Campusano, quien, sin abandonar del todo la furtividad que es propia de las amantes, ha llegado a convertirse en algo así como la "amante oficial” de San Martín. No es sin reticencias que Rojas consigna que "las tradiciones de Ricardo Palma dan a entender que haya existido entre ambos una intimidad amorosa" (292), pero como en verdad no lo dan a entender, sino que directamente lo dicen, también Rojas acaba por admitirlo.

Mal pueden las revelaciones sobre estos amores jaquear la santificación del Padre de la Patria, cuando es en el texto hagiográfico por excelencia donde se los consigna. Ricardo Rojas es quien proporciona los datos acerca de la mujer ocasional de Cádiz y acerca de la mujer no demasiado ocasional de Lima, datos que él recoge de Benjamín Vicuña Mackenna (que publicó en Chile, en 1863, una temprana biografía bien documentada de San Martín) y de las Tradiciones peruanas de Ricardo Palma. Rojas proporciona tanto esa información como las estrategias con que los relatos sobre San Martín salvan su figura de estos deslices. ${ }^{13}$ En primer lugar, la articulación de vida privada y vida pública, de manera tal que también estos amores irregulares pasan a funcionar como labor patriótica, y hasta

\footnotetext{
${ }^{13}$ Por otra parte, la concepción de la nacionalidad sostenida por Rojas, no solamente hacia los años treinta en El santo de la espada, sino ya en La restauración nacionalista del Centenario o en la Historia de la literatura argentina de 1917, con la tendencia inclusiva que incorporaba también la tradición indígena al paradigma de la argentinidad, permitiría resolver simbólicamente la cuestión del verdadero origen familiar de San Martín, cuestión que recientemente motivó el citado reclamo de un estudio de ADN. En buena medida, los términos del debate actual son más estrechos que los planteados por Rojas, y la concepción de la identidad sostenida en la discusión sufre un atraso de aproximadamente noventa años.
} 
podrían integrarse a su foja de servicios. ${ }^{14}$ En segundo lugar, la espiritualización del romance-dice Rojas de Rosa Campusano: “también parece que haya sido su Egeria, pues era una mujer espiritual” (293)-, por lo cual, después de reconocer la debilidad de la carne, se efectúa un desvanecimiento de toda materialidad corporal. En tercer lugar, la atenuación de la gravedad moral del episodio en consideración a su carácter único y excepcional (curiosamente, el argumento no se debilita por el hecho de que se cite más de un caso único). ${ }^{15}$ Y por último, en cuarto lugar, una compensación moral basada en el alto sentido de la discreción de San Martín: "Si San Martín pudo llegar a ser su amante, lo fue 'de tapadillo’, como en el Perú se dice”. ${ }^{16}$

Los procedimientos empleados por Rojas para sostener a San Martín, pero para sostenerlo después de haber reconocido y registrado sus humanas debilidades, son los mismos que después se emplean en los textos que anuncian una puesta en cuestión de las versiones hagiográficas del héroe nacional (también Sarmiento y Mitre disponen de una serie de mecanismos para atenuar o compensar o corregir las flaquezas y los errores de San Martín). Es decir que los textos de canonización sanmartiniana no solo no son un despliegue apologético unidimensional, que luego podría habilitar un rescate del prócer en su humanidad, sino que constituyen un lugar de aprendizaje para esos textos que, pese a todo, insistentemente presumen contradecirlos.

LOS HÉROES DE BARRO

En la dialéctica de la construcción de los héroes nacionales, las imperfecciones contribuyen a la configuración de un héroe “perfecto". Esto es lo que los textos que sostienen la consagración histórica de San Martín comprenden bien, y en cambio los textos que periódicamente emprenden la tarea de una humanización que juzgan imprescindible, no comprenden o no quieren comprender (aceptarlo implicaría, en última instancia, aceptar que ellos mismos no tienen razón de ser).

La configuración de San Martín como Padre de la Patria contiene y resuelve el señalamiento de sus errores o debilidades humanas, no los omite. Lejos de una lógica del ocultamiento, a la que bastaría con oponerle una lógica de la develación para desarmarla, la representación de un héroe nacional incluye críticas y cuestionamientos, incluye su cotidianeidad y su realidad de carne y hueso, incluye el escrutamiento más o menos indiscreto de su intimidad. Lo que en el discurso histórico sostiene la heroicidad sanmartiniana, la posibilidad de San Martín de ser una cifra cabal de la argentinidad y también la expresión del mandato moral del deber ser de la argentinidad en el futuro, es

\footnotetext{
${ }^{14}$ Mediante este recurso de politización de lo privado, resulta ser que la amante de San Martín en Lima cumple una función esencialmente política: "Rosa podía ser un eficaz agente de San Martín”, y era "un instrumento de sus planes políticos ya que ella tenía influencia sobre hombres importantes del Perú” (Rojas 292 y 293).

${ }^{15}$ Dice Rojas: "Rosa Campusano ha quedado asociada a su nombre en las tradiciones peruanas, y ella es la única mujer que ha tenido ese privilegio en la singular y austera vida de nuestro héroe”. ${ }^{16}$ La cita se toma de Ricardo Palma, quien dice: "San Martín, antagónico en esto a su ministro Monteagudo y al Libertador Bolívar, no dio en Lima motivo de escándalo por aventuras mujeriegas. Sus relaciones con la Campusano fueron de tapadillo" (Palma 953).
} 
precisamente que la figura heroica de San Martín resiste todas esas consideraciones: que los relatos de su vida las atraviesan y que, después de atravesarlas, siguen teniendo la posibilidad de sostener al prócer en pie.

Mitre lo entiende claramente en su Historia de Belgrano: "Estas miserias -dice-, de que no están exentos los grandes hombres, no son indignas de la historia, porque ellas constituyen una especie de lección que nos enseña que todos los héroes son amasados con el barro humano" (II, 109). Un raro juego de alquimia hace que, para alcanzar la consagración de la estatua de bronce, deba previamente emplearse el barro humano (que aquí significa también carne y hueso). En ningún sentido puede el barro desmentir ni revertir la exaltación idealizada de la estatua de bronce, desde el momento en que forma parte de su composición.

La verificación de la falacia en que se fundan los textos que quieren rescatar a un San Martín humano más allá del héroe impoluto (y que es en verdad una doble falacia: primero, que los textos de canonización sanmartiniana lo deshumanizaron y no le reconocieron debilidades; segundo, que los textos que proclaman perfiles humanos, vidas íntimas y agonías interiores, van a producir un sistema de representación diferenciado respecto de aquellos relatos de consagración histórica) no concluye en una mera constatación de que una propuesta, aunque repetida y muchas veces exitosa, es, o bien inútil, o bien equívoca, o bien malintencionada.

La consagración histórica de José de San Martín contiene no solo una representación de su más terrenal humanidad: contiene también un reclamo de humanización. En efecto, en El santo de la espada Ricardo Rojas comienza diciendo:

A pesar de su enorme bibliografía, la persona de San Martín había quedado un tanto cubierta por el cúmulo de los acontecimientos políticos, económicos y militares que la historia describe. Lo que yo me he propuesto, en cambio, es pintar la personalidad de San Martín como hombre [...]. Todas estas imágenes del prócer son tan verdaderas como las de sus retratos con uniforme, y no se parecen a sus estatuas ecuestres ni a sus oleografías escolares. (9 y 11-2)

Es decir que la idea de que el héroe ha sido congelado por los discursos de la historia, por las estatuas de bronce y por las imágenes escolares, y el consiguiente anuncio de un rescate del "hombre", forma parte de la consagración de la heroicidad sanmartiniana (aparece, de hecho, presidiendo el texto de su santificación). El reclamo de la humanización de San Martín no solo no contradice su canonización histórica como gran héroe, sino que es una de sus estrategias; y esa estrategia se renueva tal como se renuevan los textos que prometen volver al hombre de carne y hueso: una y otra vez se pretende que las facetas humanas del héroe se han visto postergadas, una y otra vez se pretende que es necesario recuperarlas.

Desde este punto de vista, es difícil hablar del fracaso o de la inutilidad de los textos de humanización de San Martín. Si se considera, por lo pronto, el extraordinario poder de convicción que han conseguido sus premisas, por falsas que sean, no habría por qué pensar en un esfuerzo vano ni improductivo. El éxito de esas premisas, que ya forman parte del más pleno sentido común, y su persistencia, explicarían lo prolongada y lo insistente que es la publicación de este tipo de libros. Es curiosa, por otra parte, la manera en que se 
renueva el presupuesto de la necesidad de humanización: se vacía el espacio del discurso histórico, definiéndolo en términos de deshumanización, pero se vacía también el espacio de los anteriores emprendimientos de humanización del prócer: esa tarea se presenta cada vez como inédita, nunca antes intentada, siempre por hacerse. Cada uno de esos textos -hasta el último avatar de los rescates del hombre concreto, el Don José de don José Ignacio García Hamilton- crea un vacío discursivo en el cual instalarse, y crea la ficción de su inédita originalidad.

En definitiva, no son sino los propios textos que prometen humanizar al prócer los que fundan la creencia ficticia de una previa deshumanización. El héroe deshumanizado no existe más que en los textos que reclaman un héroe más humano. No existe en el discurso de la historia, pero sí existe en los discursos que claman por un rescate del hombre real más allá de la estatua ideal. Y ocurre que estos textos -textos menores, laterales, a veces incluso muy precarios- parecen tener más peso, al menos para esta cuestión, que los textos centrales de la historiografía nacional.

\section{BibliogRAFÍA}

Bucich Escobar, Ismael. San Martín. Diez capítulos de su vida íntima. Buenos Aires:

Anaconda, 1939.

Ibarguren, Carlos. San Martín íntimo. Buenos Aires: Peuser, 1950.

Mitre, Bartolomé. Historia de Belgrano y de la independencia argentina. Buenos Aires:

Biblioteca Argentina-Librería La Facultad, 1927.

Historia de Belgrano y de la independencia argentina. Buenos Aires: Biblioteca Argentina-Librería La Facultad, 1927.

Historia de San Martín y de la emancipación sudamericana. Buenos Aires: Biblioteca La Nación, 1903.

“Las cuentas del Gran Capitán”. Obras completas (Volumen XII). Buenos Aires:

Edición ordenada por el H. Congreso de la Nación Argentina, 1949.

Oriol I Anguera, A. Agonía interior del muy egregio señor José de San Martín y Matorras. Buenos Aires: Librería del Colegio, 1954.

Palma, Ricardo. Tradiciones peruanas. Madrid: Aguilar, 1957.

Rojas, Ricardo. El santo de la espada. Buenos Aires: Losada, 1940.

Rubens, Erwin Félix. Perfil humano de San Martín. Buenos Aires: Eudeba, 1978.

Sarmiento, Domingo F. Viajes por Europa, África y América. Buenos Aires: Archivos. FCE, 1993.

Vida de San Martín. Buenos Aires: Claridad, 1950.

Thomas, José Luis. Los amores ocultos de San Martín. Buenos Aires: El Francotirador, 1998.

Varela, Mirta. Los hombres ilustres del Billiken. Buenos Aires: Colihue, 1994.

Wienhauser, Santiago. Fortaleza sanmartiniana. Bosquejo psicológico. Buenos Aires:

Theoría, 1964. 